\title{
CORRECTION
}

\section{Correction to: Phosphate, phosphoric acid and phosphogypsum natural radioactivity and radiological hazards parameters}

\author{
Korany. A. Korany ${ }^{1}$ (D) A. M. Masoud ${ }^{2}$ - O. E. Roshdy ${ }^{2}$ - Z. A. Alrowaili ${ }^{3} \cdot$ T. F. Hassanein ${ }^{4} \cdot$ M. H. Taha ${ }^{2}$
}

Published online: 30 June 2021

๑) Akadémiai Kiadó, Budapest, Hungary 2021

\section{Correction to: \\ Journal of Radioanalytical and Nuclear Chemistry https://doi.org/10.1007/s10967-021-07796-8}

In the original publication of the article, third and fifth author's name was misspelt. The correct names are given in this correction.

Publisher's Note Springer Nature remains neutral with regard to jurisdictional claims in published maps and institutional affiliations.

The original article can be found online at https://doi.org/10.1007/ s10967-021-07796-8.

Korany. A. Korany

korany81@hotmail.com

1 Department of Physics, Nuclear Materials Authority, P.O. Box 530, ElMaadi, Cairo, Egypt

2 Department of Chemistry, Nuclear Materials Authority, P.O. Box 530, ElMaadi, Cairo, Egypt

3 Department of Physics, College of Science, Jouf University, P.O. Box: 2014, Sakaka, Saudi Arabia

4 Chemistry Department, Faculty of Science, Helwan University, Helwan, Cairo 11795, Egypt 